\title{
Evolution of the Hydrological and Hydrodynamic Characteristics in the Outlet Reach of Xiangjiang River
}

\author{
Wang Xu \\ University of Science \& Technology Beijing
}

China Institute of Water Resources and Hydropower Research

NO.1 South Yuyuantan, Haidian district, Beijing, P. R. of China

Tel: 86-152-0145-6974Ｅ-mail: wangxu8568658@163.com

\section{Yan Denghua (Corresponding author)}

China Institute of Water Resources and Hydropower Research

NO.1 South Yuyuantan, Haidian district, Beijing, P. R. of China

Tel: 86-010-6878-5511Ｅ-mail:denghuay@gmail.com

Xiao Weihua

China Institute of Water Resources and Hydropower Research

NO.1 South Yuyuantan, Haidian district, Beijing, P. R. of China

Tel: 86-010-6878-5511 E-mail: xwsen998@163.com

\section{Zhu Weiyao}

University of Science \& Technology Beijing

NO.30 Xueyuan Road, Haidian district, Beijing, P. R. of China

Tel: 86-137-1750-9588Ｅ-mail: weiyaook@ sina.com

Yuan Yong

Beijing Forestry University

China Institute of Water Resources and Hydropower Research

NO.1 South Yuyuantan, Haidian district, Beijing, P. R. of China

Tel: 86-152-0128-9556Ｅ-mail: Yongdt@126.com 


\title{
IIMacrothink
}

Received: August 15, 2012

doi:10.5296/jee.v3i1.2248
Accepted: September 24, 2012 Published: December 1, 2012 URL: http://dx.doi.org/10.5296/jee.v3i1.2248

\begin{abstract}
In this study, a one-dimensional hydrodynamic model in the lower reaches of Xiangjiang River is constructed to conduct a simulation of the hydrodynamic characteristics of the lower reaches in Xiangjiang River. In this model, the backwater effect of Dongting Lake is taken into account to define the range of the outlet reach of Xiangjiang River. Observed hydrological data in a rather long period, i.e. 1980-2008, in Xiangjiang River and Dongting Lake basin are systematically collected, to further analyze the evolution pattern of hydrological and hydrodynamic characteristics in the outlet reach of Xiangjiang River. The results show that the range of the outlet reach of Xiangjiang River is $100 \mathrm{~km}$ away further up from the lake inlet, which is within the region of Xiangtan, which is within Xiangtan region. The backwater effect can be found annually in the period from June to October. The findings from this study may have implications on studies of the evolution of river-lake relation and the eco-environmental effect, and provide scientific basis for water resources development and eco- environmental protection in the outlet reach of Xiangjiang River.
\end{abstract}

Keywords: Outlet reach, Backwater effect, Hydrological and hydrodynamic characteristics, Xiangjiang River 


\section{Introduction}

The backwater effect refers to the hydrological phenomenon that a natural river running into larger rivers or lakes, which reduces the flow discharge and raises the water level in a certain section. The backwater effect is easier to be found, especially in a relatively plain river channel (Ceyhun Ozcelik et al., 2009; He, et al., 2008). The river into larger rivers and lakes has particular hydrodynamic conditions and remarkable eco-environmental effect under the backwater effect, which is mainly manifested in the following phenomena: the flow rate of the backwater reach slows down, which results in sediment accumulation and reduced discharging capacity of the river channel so as to cause serious potential flood risks; the reduced degradation and dilution capacity of the backwater reach brings about serious problems on water environment security(Ding et al.,2011).Therefore, it is of great significance to study the evolution trend of the hydrological and hydrodynamic characteristics under backwater effect.

At present, few in-depth studies on hydrological and hydrodynamic characteristic evolution on the outlet reach under the backwater effect have been reported at home and abroad The length of the backwater-affected reach (i.e. the outlet reach range) is defined mainly through local practices or analysis in terms of the water level change in a certain monitoring section to determine whether the section is within the backwater-affected reach, so as to further determine the length of the outlet reach(Peng, et al.,2002; Yi, et al.,2007). Such method is nevertheless far from accurately reflecting the specific condition. Some researchers simulated the backwater effect condition of a reservoir with simple examples based on a mathematical model of water flow, in order to study the evolution pattern of the backwater-affected length of the river running from the reservoir (Simin et al., 2008). However, the study by dynamically simulating the flow velocity evolution based on a hydrodynamic model, which may defines the length of the outlet reach of the river running into the larger river or lake, has not been widely performed yet. In addition, although some researchers have made analyses on the evolution of water level, flow, and fall based on the hydrological monitoring data, they have not clarified the evolution pattern of hydrological and hydrodynamic characteristics through in-depth analysis of the changes of the hydrological and hydrodynamic characteristics.

The outlet reach of Xiangjiang River into Dongting Lake is densely populated with relatively well developed cities and villages on both sides. The backwater effect of Dongting Lake is one of the factors contribute to the fragile eco-environment in this region. Therefore, in order to solve the ecological problems in the outlet reach of Xiangjiang River, we have to identify the range of the river outlet reach and the evolution pattern of its hydrological and hydrodynamic characteristics. On the basis of hydrodynamic simulation and analyses of long-term hydrological observation data collected in the lower reaches in Xiangjiang River, this study defines the spatial range of the backwater affected outlet reach of Xiangjiang River, and performs primary analysis on the evolution of its hydrological and hydrodynamic characteristics, which may provide scientific basis for the comprehensive treatment and development of water resources in the outlet reach of the mainstream of Xiangjiang River and the water environment protection. This study may also lay a theoretical foundation for the 
study of other similar rivers naturally running into larger rivers or lakes.

\section{Study Area}

Dongting Lake is located in the north of Hunan province and south to the middle reaches of Yangtze River, extending from approximately $28^{\circ} 30^{\prime} \mathrm{N}$ and $111^{\circ} 40^{\prime} \mathrm{E}$ to $30^{\circ} 20^{\prime} \mathrm{N}$ and $113^{\circ} 10^{\prime}$.. Four tributaries named Xiang, Zi, Yuan and Li River flow into it from the south and three diversion channels from the Yangtze River named Songzi, Taiping, and Ouchi mouth flow into it from the north. It is one of the most important storage and regulation lakes along Yangtze River. Xiangjiang River, an important first level branch of Yangtze River, is with a basin of $94,660 \mathrm{~km}^{2}$. Its mainstream is $856 \mathrm{~km}$ long with an average slop of $0.134 \%$, while the lower reaches of river channel is much gentler, with an average slop of $0.05 \%$. As shown in Figure 1.Xiangjiang River, originating from Haiyang Mountains in Lingui County of Guangxi Province, enters the territory of Hunan Province from Dong'an County, then flows into Dongting Lake at Haohekou after passing Yongzhou, Hengyang, Zhuzhou, Xiangtan and Changsha, and finally converges into Yangtze River through Chenglingji.

Dongting Lake has the annual mean runoff of 301.8 billion $\mathrm{m}^{3}, 111.9$ billion $\mathrm{m}^{3}$ of which comes from Yangtze River, accounting for $37 \%$ of the total inlet, while 164.7 billion $\mathrm{m}^{3}$ comes from Xiang, Zi, Yuan, Li Rivers, accounting for 54.6\%. Water from Xiangjiang River approximately accounts for $39 \%$ of that from the four rivers.. Xiangjiang River lies in the humid region in the south of China with great precipitation. There are 140 160 rain days annually across the basin, and the annual mean precipitation is $1,472.9 \mathrm{~mm}$. The precipitation varies greatly within a year and between years under the influence of the monsoon climate, with over $60 \%$ falling densely in April to July especially in May and June, and is thus in an uneven spatial and temporal distribution. The lower reaches of Xiangjiang River starts from the estuary of Lei River in Hengyang. This paper primarily focuses on the lower reaches of Xiangjiang and the region of Dongting Lake.

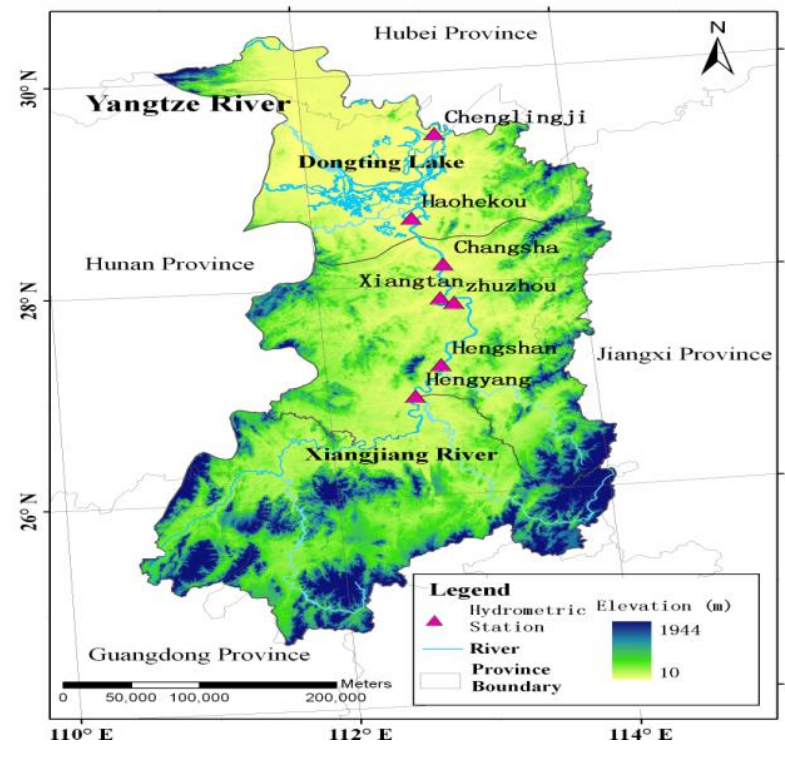

Figure 1. Sketch of the study area 


\section{Materials and methods}

\subsection{Data Application}

This paper has collected hydrological data of the hydrometric stations in the Xiangjiang River and Dongting Lake during 1980-2008, and the main research stations for the collection of the data include Chenglingji (Qilishan) Station in Dongting Lake, Changsha, Xiangtan, Zhuzhou, Hengshan and Hengyang stations in lower reaches of Xiangjiang River, while the collected data contains the aspects of daily mean runoff, daily mean water level, and cross-sections diagram, etc.

Table 1. Data of the main stations in the lower reaches of Xiangjiang River basin

\begin{tabular}{lllll}
\hline No. & Station & $\begin{array}{l}\text { Distance from } \\
\text { Estuary } / \mathrm{km}\end{array}$ & Elevation $/ \mathrm{m}$ & $\begin{array}{l}\text { Width of river } \\
\text { bottom } / \mathrm{m}\end{array}$ \\
\hline 1 & Haohekou & 0 & 19.04 & 844 \\
2 & Changsha & 60 & 21.81 & 633 \\
3 & Xiangtan & 102 & 23.27 & 564 \\
4 & Zhuzhou & 138 & 26.02 & 521 \\
6 & Hengshan & 253 & 39.31 & 501 \\
\hline
\end{tabular}

\subsection{Definition of the Range of Outlet Reach}

Influenced by the backwater effect of the receiving water, water level is raising and water velocity is reducing resulted from the water accumulations in estuaries. Therefore the stream velocity is in a decreasing trend from the certain area in up-river to the estuary. Through the water velocity distribution simulation conducted along the river under backwater effect, the catastrophe point of the velocity may be found. So the length of reach under the influence of backwater effect could be determined, which is the range of the outlet reach..

The flow in the reach under backwater effect belongs to open-channel slowly varying unsteady current, and the flowing rules could be described with Saint-Venant equation system (Christina W, 2005; Hu et al., 2001). The equation system of 1-D non-constant flow:

$$
\left\{\begin{array}{l}
B \frac{\partial Z}{\partial t}+\frac{\partial Q}{\partial x}=q_{L} \\
\frac{\partial Q}{\partial x}+\frac{\partial}{\partial x}\left(\frac{\alpha Q^{2}}{A}\right)+g A \frac{\partial Z}{\partial x}+g \frac{n^{2} Q|Q|}{A R^{4 / 3}}=0
\end{array}\right.
$$


where: $\mathrm{x}$ and $\mathrm{t}$ are the variables for the distance and time along the river; $\mathrm{A}$ is the cross section area of flow; $Q$ is the discharge; $Z$ is the water level; $B$ is the water surface width; $\mathrm{q}_{\mathrm{L}}$ is the discharge of flanking inflow for the unit river length: $\mathrm{R}$ is the hydraulic radius; $\mathrm{n}$ is the roughness rate: $\alpha$ is the dynamic correction coefficient and $\mathrm{g}$ the acceleration of gravity.

Preissmann four points weighted implicit difference scheme is used in the model with the hydraulic elements in the beginning of the period as the mean hydraulic elements during this period to make discrete on equations (1) and the linearized treatment on difference equation, through which the following equation system is obtained:

$$
\begin{aligned}
& -Q_{i}+C_{i} H_{i}+Q_{i+1}+C_{i} H_{i+1}=D_{i} \\
& E_{i} Q_{i}-F_{i} H_{i}+G_{i} Q_{i+1}+F_{i} H_{i+1}=\Phi_{i}
\end{aligned}
$$

Where:

$$
\begin{aligned}
& C_{i}= \frac{\Delta x_{i}}{2 \theta_{1} \Delta t} B_{i+1}^{j} / 2 \\
& D_{i}= \frac{\Delta x_{i}}{\theta_{1}} q_{L}+\frac{1-\theta_{1}}{\theta_{1}}\left(Q_{i}^{j}-Q_{i+1}^{j}\right)+C_{i}\left(H_{i}^{j}-H_{i+1}^{j}\right) \\
& E_{i}= \frac{\Delta x_{i}}{2 \theta_{2} \Delta t}-2 u_{i+1}^{j} / 2+\frac{g}{2 \theta_{2}}\left(\frac{A|Q|}{K^{2}}\right)_{i}^{j} \Delta x_{i} \\
& G_{i}= \frac{\Delta x_{i}}{2 \theta_{2} \Delta t}+2 u_{i+1}^{j} / 2+\frac{g}{2 \theta_{2}}\left(\frac{A|Q|)^{j}}{K^{2}}\right)_{i+1}^{\Delta x_{i}} \\
& F_{i}=\left(g A-B u^{2}\right)_{i+1}^{j} / 2 \\
& \qquad \frac{\Delta x_{i}}{2 \theta_{2} \Delta t}\left(Q_{i}^{j}+Q_{i+1}^{j}\right)+\frac{2\left(1-\theta_{2}\right)}{\theta_{2}} \frac{u_{i+1}^{j}}{2}\left(Q_{i}^{j}-Q_{i+1}^{j}\right) \\
& \Phi_{i}= \\
&+\frac{\left(1-\theta_{2}\right)}{\theta_{2}} \frac{\left(g A-B u^{2}\right)_{i+1}^{j}}{2}\left(H_{i}^{j}-H_{i+1}^{j}\right)+\frac{\Delta x_{i}}{\theta_{2}}\left(\left.u^{2} \frac{\partial A}{\partial x}\right|_{z}\right)_{i+1}^{j} / 2
\end{aligned}
$$

Where: the subscript of each variable indicates the number of sections, while the superscript indicates the number of periods; $H$ is the water depth; $U$ is the velocity; $\theta$ is the Difference weight; From Equation (4) to (9), coefficients $C_{i}, D_{i}, E_{i}, F_{i}, G_{i}, \Phi_{i}$ in Equation (2) and (3) are the undetermined coefficients of the river section of $i$, which are only correlated to geometric parameters, roughness rate and initial conditions of the river channel. Thus, it's a system of linear algebraic equations. $2 \mathrm{~N}$ equations with $2(\mathrm{~N}+1)$ variables may be formulated in $\mathrm{N}$ river sections, which can, along with the boundary conditions of both ends of the river channel, formulate a closed algebraic equation system. The coefficient matrix of this closed algebraic equation system, as a four diagonal sparse matrix, can be solved by means of Phase 


\section{Macrothink}

method, from which the water level, discharge and water velocity of each section could be obtained.

\subsection{Data Normalization}

Since the value of discharge and water level of the hydrometric stations shows different dimensions, Min-Max Standard method is used to make linear transformation on the initial data to map the values of water levels and discharges into the interval of $[0,1]$, so as to make comparison on the changing process of discharge and water level. The equation is as follows:

$$
X_{n}=\left(X_{o}-X_{\mathrm{min}}\right) / X_{\mathrm{ma}}-X
$$

Where: $X_{n}$ is the new data; $X_{0}$ is the original data; $X_{\max }$ and $X_{\min }$ is respectively the maximum and minimum value.

Map the transformed data into the discharge-water level curves ranging with the time, and then compare the changing process of the curves, we may obviously observe the changing rules of water level and discharge under the backwater effect, and we may determine the time distribution rules of the backwater effect.

\section{Results and Discussion}

\subsection{Velocity Distribution and Range of Outlet Reach}

With the model, we have to calculate the data in the selected region within the water reach between Hengyang Station and Haohekou section, with the boundaries of sections in Hengyang Station and Haohekou. Select the real measured-data of Xiangtan Station and Changsha Station in the year of 2006 to conduct the calibration and validation, the results of which are shown in Figure 2. By comparison of the actually measured and the computed water level in Xiangtan Station and Changsha Station, the simulated and actual results are likely to be the same. In this condition, this model may be further adopted in the analysis of the hydrodynamics changing trend of backwater effect water. The parameters required in this model include: numerical coordinates of sampling points, river width, river bottom elevation, bank slop, roughness, initial water depth and discharge 

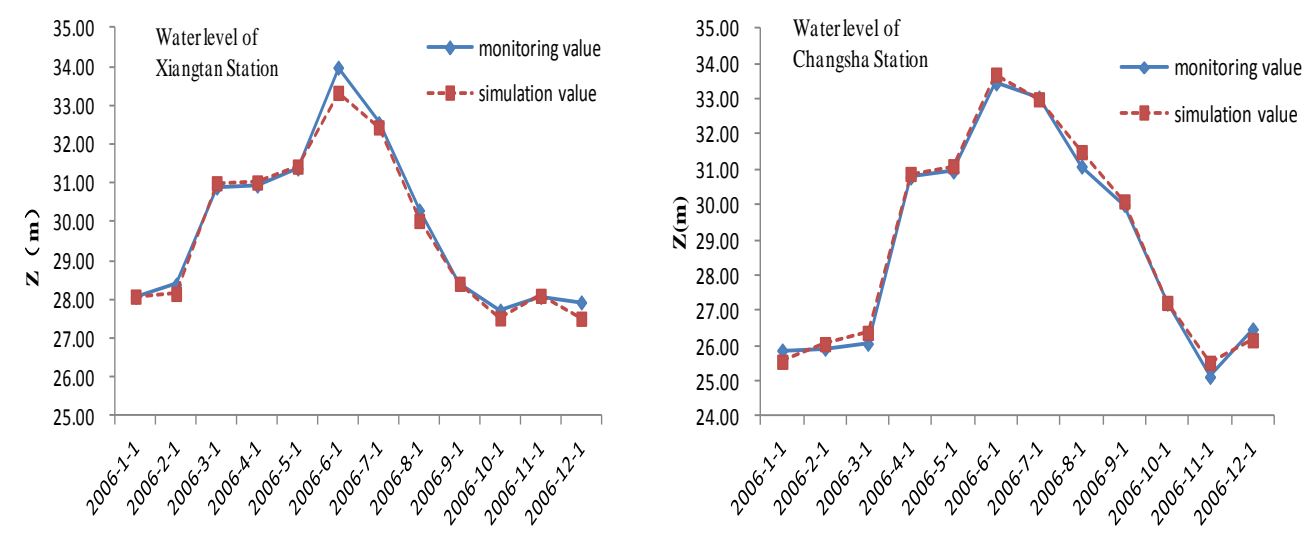

Figure 2. Analysis of water level validation of Xiangtan and Changsha Station

The computed results of water velocity along the lower reaches of Xiangjiang River are as shown in Figure 3. According to this figure, we may found that, under the backwater effect of Dongting Lake, there is remarkable change in water velocity distribution along the channel of Xiangjiang River. The water flows quite slowly near the estuary, the velocity at Haohekou station is $0.048 \mathrm{~m} / \mathrm{s}$. When the distance to the estuary increases, the velocity is increasing until it becomes steady. In this process, the distance between the corresponding position of the catastrophe water-velocity point and the estuary is the length of the estuary reach of Xiangjiang River.
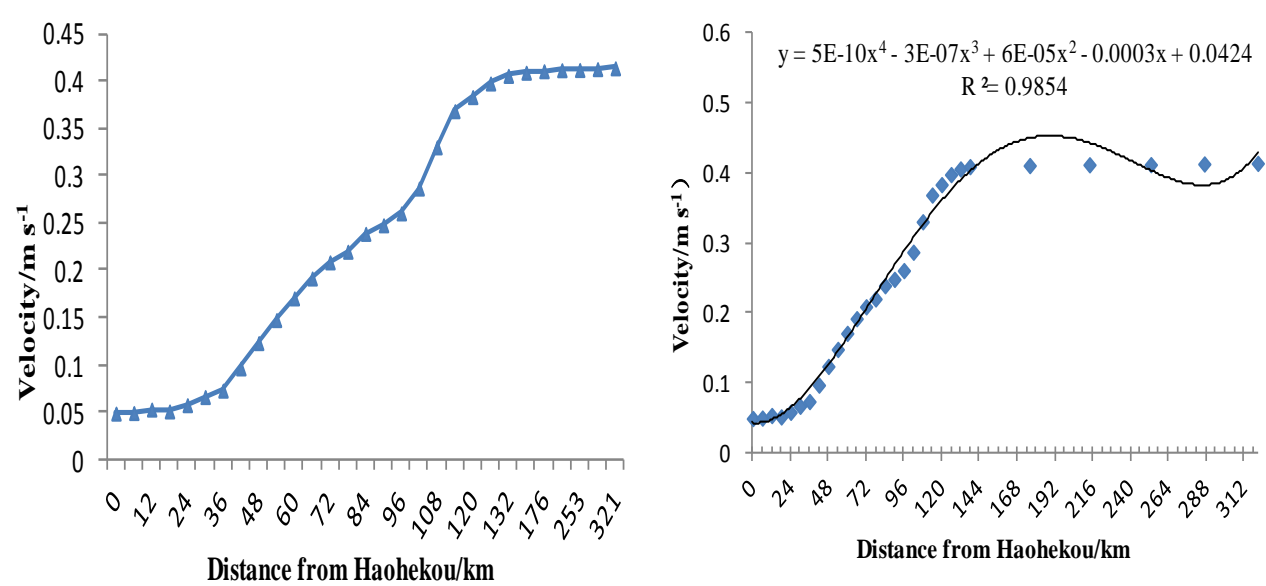

Figure 3. Fitting curve of the distribution of the water velocity under backwater effect

Discrete the water velocity along the channel of the lower reaches of Xiangjiang River, with the polynomial of equations, we may obtain the equation $y=5 E-10 x^{4}-3 E-07 x^{3}+6 E-05 x^{2}-$ $0.0003 x+0.0424$. Relative coefficient $R=0.9854$ indicates the correlated coefficient is sound. With the application of definition of the changing point of curve concavity, the discrete equation may be calculated. Find out the inflection point of the fitted cure, the catastrophe point of water velocity then may be determined. 


$$
\left\{\begin{array}{l}
y^{\prime}=2 \times 10^{-9} \mathrm{x}^{3}-9 \times 10^{-7} \mathrm{x}^{2}+1.2 \times 10^{-4} \mathrm{x}-0.0003 \\
y^{(2)}=6 \times 10^{-9} \mathrm{x}^{2}-1.8 \times 10^{-6} \mathrm{x}+1.2 \times 10^{-4} \\
y^{(3)}=1.2 \times 10^{-8} \mathrm{x}-1.8 \times 10^{-6}
\end{array}\right.
$$

Given $\mathrm{y}(2)=0 ; \quad \mathrm{y}(3) \neq 0$, then $\mathrm{x}=100$ or $\mathrm{x}=200$

According to the figure above, the backwater-affected water velocity is basically steady when $x=200$, which indicates it's not the catastrophe point. Then, the water velocity is in sudden change when $x=100$. Therefore, a conclusion can be drawn that the estuary reach of Xiangjiang River into Dongting Lake is $100 \mathrm{~km}$ approximately from Xiangtan Station to Haohekou, which is within the region of Xiangtan Station.

\subsection{Changing Processes of Discharge and Water Level}

Xiangjiang River, with the influence of the backwater effect, the variation and situation of which are related to the local precipitation runoff in the basin, as well as the changing water level of Dongting Lake. The variation manifested in the changing trend of the water level and discharge ${ }^{[14]}$. Select the data of monthly mean discharge and water level in Xiangtan Station in the period of 1980 2008, with the adoption of the Min-max Standard Method which is used to make standardization treatment on the initial data, we may then map the discharge-water level curve varying with the time, which is as shown in Figure 4.

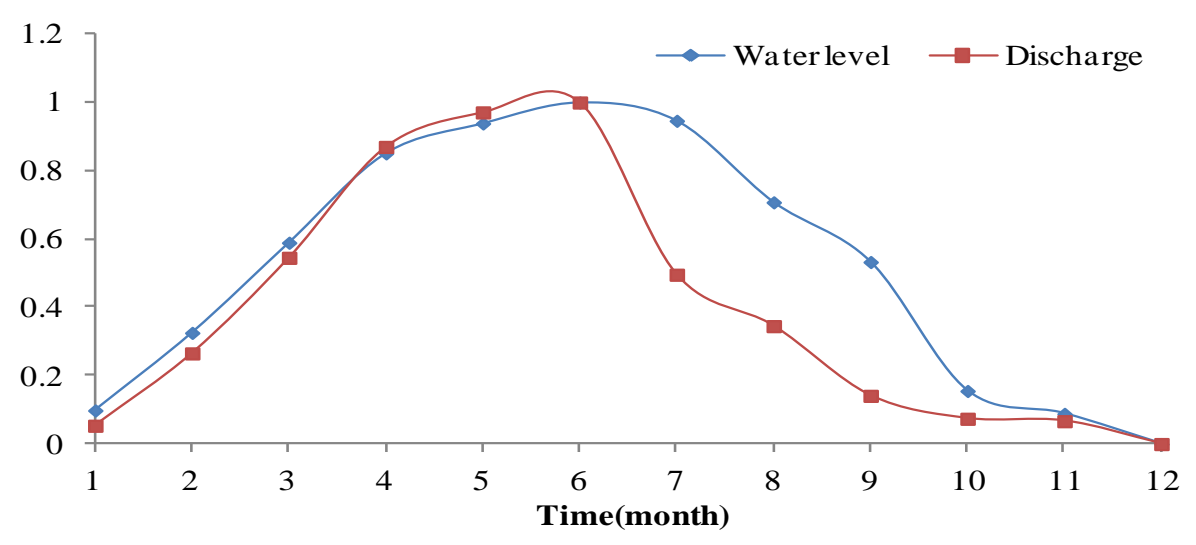

Figure 4. Variation of the mean water level and discharge of Xiangtan Station during 1980 and 2008

According to the figure, the actually measured water level and discharge changes are better correlated in Xiangtan Station during the periods from January to June and November to December. However, the discharge reduces sharply with relatively high water level in the period from July to October. It is for the reason that the coming water from the up water of Xiangjiang River to Dongting Lake rises in this period; and in July to October, the Yangtze River is in main flood season, some water has to be conducted into the Dongting Lake. With the backwater effect, the water flow from upper reaches is blocked, which leads to the rising water level, slow water velocity, and decreasing discharge in this region. 


\subsection{Change in Fall of Water Level}

Under the backwater effect of water level in Dongting Lake, the estuary reach of Xiangjiang River suffers from the resulted water block, which influences greatly on the water level of this section, and leads to gentle water surface. This situation may be described as the fall of water level. In order to clearly express the change of water level falls in outlet reach of Xiangjiang River under the backwater effect, the falls of water levels between Xiangtan Station and Changsha Station, Chenglingji Station (Qilishan) and Changsha station are selected for comparison. Through analysis of the water level data of the hydrometric stations during 1980 2008, the annual monthly mean water level then may be calculated for comparison and analysis. As shown in Table 2 and Figure 5(A), the average fall of water levels between Xiangtan Station and Changsha Station during January to June and November to December is approximately $1.8 \mathrm{~m}$, while the water level in Dongting Lake during July to October remains high, and the water surface gradient is gradual with the mean value of only $0.58 \mathrm{~m}$.

Table 2. Monthly mean fall of water level between Xiangtan and Changsha Station during 1980 2008 unit: $\mathrm{m}$

\begin{tabular}{lccccccccccccc}
\hline Station & Jan. & Feb. & Mar & Apr. & May & Jun. & Jul. & Aug. & Sep. & Oct. & Nov. & Dec. \\
\hline Xiangtan & 29.24 & 30.11 & 31.13 & 32.14 & 32.48 & 32.72 & 32.51 & 31.59 & 30.91 & 29.46 & 29.20 & 28.86 \\
Changsha & 27.34 & 28.15 & 29.08 & 30.32 & 30.76 & 31.41 & 32.09 & 31.10 & 30.27 & 28.70 & 27.54 & 27.04 \\
Fall & 1.90 & 1.96 & 2.05 & 1.82 & 1.71 & 1.30 & 0.42 & 0.49 & 0.64 & 0.76 & 1.66 & 1.82 \\
\hline
\end{tabular}
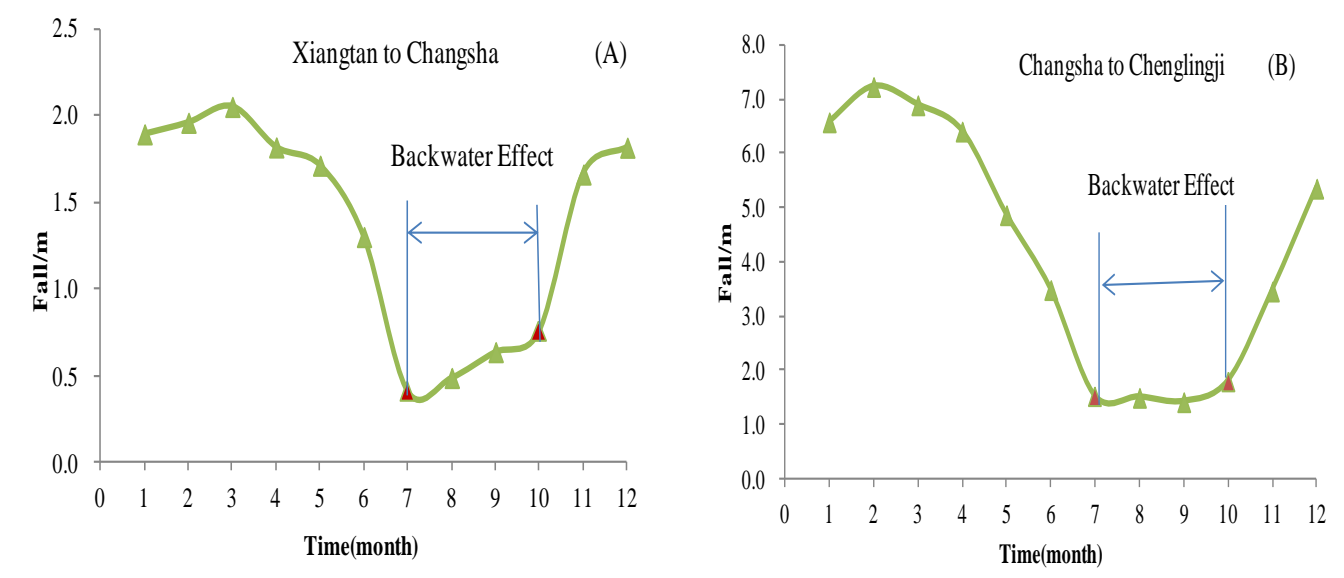

Figure 5. Annual Fall of water level of stations

Table 3 and Figure 5(B) indicate that the mean fall of water level during the period from January to June and November to December between Changsha Station and Chenglingji 
(Qilishan) is $5.54 \mathrm{~m}$ approximately, while the mean fall during July to October is only $1.56 \mathrm{~m}$ between the two stations under the backwater effect of the high water level in Dongting Lake.

Table 3. Monthly mean fall of water level between Chenglingji and Changsha Station during 1980 2008 unit: $m$

\begin{tabular}{lccccccccccccc}
\hline Station & Jan. & Feb. & Mar. & Apr. & May & Jun. & Jul. & Aug. & Sep. & Oct. & Nov. & Dec. \\
\hline Changsha & 27.34 & 28.15 & 29.08 & 30.32 & 30.76 & 31.41 & 32.09 & 31.10 & 30.27 & 28.40 & 27.54 & 27.04 \\
Chenglingji & 20.76 & 20.92 & 22.18 & 23.91 & 25.89 & 27.92 & 30.57 & 29.59 & 28.85 & 26.60 & 24.07 & 21.68 \\
Fall & 6.58 & 7.23 & 6.89 & 6.41 & 4.87 & 3.49 & 1.52 & 1.51 & 1.43 & 1.80 & 3.46 & 5.36 \\
\hline
\end{tabular}

Through analysis of the level fall between the representative hydrometric stations, it is indicated that Dongting Lake receives the floods from Yangtze River during the period from July to October, which causes serious backwater phenomenon and less water surface gradient under the backwater effect of the high water level of Dongting Lake. However, during the period of January to June and from November to December, there is no or little backwater effect on the estuary reach of Xiangjiang River, which results in great water level gradient due to the low flow and water level of Dongting Lake.

\section{Conclusions}

The backwater effect of Dongting Lake on Xiangjiang River in the main floods season is a naturally occurred phenomenon. It is caused by specific hydrodynamic conditions and may result in remarkable eco-environmental effect, which is mainly manifested in such aspects as channel flow blocking, sediment deposition, influence on the security of water environment. In this study, hydrological data in a long period in the basin are used to study the definition of the range of the outlet reach in Xiangjiang River based on the hydrodynamic model and hydrological statistic method, and to make further clarification on the evolution patterns of the hydrological and hydrodynamic characteristics of the outlet reach of Xiangjiang River. The result indicates that the water flows slowly at the estuary of Xiangjiang River into Dongting Lake, and the water velocity becomes gradually faster slightly backward to the upper reach until being steady. The catastrophe point of the water velocity is found and the length of the outlet reach of Xiangjiang River is determined to be $100 \mathrm{~km}$ and extend to Xiangtan region. Based on the evolution trend of the relationship between water level-flow as well as the relationship between water level-level falls, it is discovered that the backwater effect of Dongting Lake on Xiangjiang River usually occurs during the period from June to October. Further studies are still necessary in addition to the determined evolution patterns of hydrological and hydrodynamic characteristics of the outlet reach of Xiangjiang River under the backwater effect of Dongting Lake.

\section{Acknowledgement}

This work was supported by National Program on Key Basic Research Project of China (973 
Program) (No.: 2010CB951102); the National Major Science and Technology Project during the twelfth Five-year Plan (No.2012BAC19B03).

\section{References}

Ceyhun Ozcelik., \& Mustafa Dogan. (2009) Investigation of wave attenuation mechanism under the downstream backwater effect Flow Measurement and Instrumentation, (20), 180-188.

Christina W. Tsai. (2005). Flood routing in middle-sloped rivers-wave characteristics and downstream backwater effect. Journal of Hydrology, 308, 151-167

Ding Xianwen., \& Li Xiaofeng. (2011). Monitoring of the water area variations of Lake Dongting in China with ENVISATASAR images. International journal of Applied Earth Observation and Geoinformation, (13), 894-901

Hongming He., Qian Yu, \& Jie Zhou et al. (2008). Modeling complex flood flow evolution in the middle Yellow River basin. China Journal of Hydrology, 353, 76-92

HU He-ping., HUANG Guo-ru., \&RUI Xiao-fang., et al., (2001) Research on the level and velocity calculation method for the back flow river. International Journal Hydroelectric Energy, 19(2), 25-27.

PENG Wen-qi., XUE Hai., \& SUN Dong-po., et al., (2002). Study on numerical simulation of river sink. Journal of Hydrological Engineering, (1), 16-22.

Simin Munier., Xavier Litrico., \& Gilles Belaud. (2008). Distributed approximation of open-channel flow routing accounting for backwater effects. Advances in Water Resources, (31), 1590-1602.

YI Guang-sheng., WU Gao-zhuang., \& LIU Yang-ming. (2007). Analysis of jacking influence of Jieya River to Heilongjiang River. Water Resources \& Hydropower of Northeast China, 25(1), 3-5. 